Transactions, SMiRT-25

Charlotte, NC, USA, August 4-9, 2019

Division II (Fracture Mechanics and Structural Integrity)

\title{
THE HUGE MISSING FACTOR IN LBB ANALYSIS - HOW A CIRCUMFERENTIAL THROUGH-WALL-CRACK IN A PIPE SYSTEM CHANGES THE FLEXIBILITY AND REDUCES THE APPLIED MOMENTS
}

\author{
G. Wilkowski ${ }^{1}$, M. Uddin, F.W. Brust, S. Kalyanam, \\ ${ }^{1}$ Engineering Mechanics Corporation of Columbus (Emc ${ }^{2}$ ), Columbus, OH, USA \\ (contact: gwilkowski@emc-sq.com)
}

\begin{abstract}
In the nuclear industry leak-before-break (LBB) analyses have been conducted for decades. Typically the uncracked piping normal operating forces and moments are applied in a cracked-pipe analytical procedure to determine normal leakage, and the combined forces and moments under normal operating condition and safe shutdown earthquake (SSE) seismic loading (N+SSE) are used in a fracture analysis to predict margins on "failure". This evaluation has been performed in deterministic analyses such as NRC SRP 3.6.3, as well as in probabilistic analyses (i.e., xLPR, PRAISE, NURBIT, PROST) that use a number of independent deterministic models with the uncracked piping forces and moments (or stresses). The International Piping Integrity Research Program (IPIRG) which ran from about 1990 to 1998 was first to provide some interesting insights to typical LBB behaviors. In that program, pipe system tests were conducted with simulated seismic loadings which were designed based on finite element analysis (FEA) of the pipe system. The test results showed a large margin on LBB due to a number of factors which were not fully recognized at that time. One of the key factors was recognized in 2011 when the Argentinian Atucha II PHWR plant was analyzed using a full FE model that included the containment building, reactor pressure vessel (RPV), steam generator (SG), pumps, main coolant line, surge lines, pressurizer and main steam lines and all the supports from the components/pipes to the building. It was found from this robust FE modeling effort that when circumferential through-wall cracks were put in the highest stressed locations, the applied moment dropped for both normal operating and N+SSE loading as the crack length increased. With loading three (3) times higher than SSE loads, the through-wall crack size for causing a double ended guillotine break (DEGB) was greater than $90 \%$ of the circumference. Similar results were also found for a petrochemical pipe system where thermal expansion stresses are much higher when compared to other primary stresses (pressure, gravity). Even with very low toughness materials of petrochemical plant (due to high temperature hydrogen attack), the critical crack size leading to DEGB was greater than $80 \%$. The implication of this work is that pragmatically a DEGB is not a critical concern for nuclear plant operation, and efforts would be better focused on the potential for a small-break loss-of-coolant accident (SB-LOCA).
\end{abstract}

\section{INTRODUCTION}

In the nuclear industry, leak-before-break (LBB) analyses have been conducted for decades. Typically, the uncracked piping normal operating forces and moments are applied in a cracked-pipe analytical procedure to determine normal leakage, and the combined forces and moments under normal operating condition and safe shutdown earthquake (SSE) seismic loading (N+SSE) are used in a fracture analysis to predict margins on "failure". This evaluation has been performed in deterministic analyses such as US NRC SRP 3.6.3, as well as in probabilistic analyses (i.e., xLPR, PRAISE, NURBIT, PROST) that use a number of independent deterministic models with the uncracked piping forces and moments (or stresses). 
The International Piping Integrity Research Program (IPIRG) which ran from about 1990 to 1998, first provided some insights into these behaviors. In that program, pipe system tests were conducted with simulated seismic loadings, albeit it was not a real pipe system as built for service. In the design and analyses of those pipe system tests, finite element (FE) models of the entire pipe system were used and large margins were found due to a number of factors, of which not all of them were recognized until about 2011. In 2011 (Wilkowski et al. 2011), a full FE model was created for the Argentinian Atucha II PHWR plant including; the containment building, reactor pressure vessel (RPV), steam generator (SG), pumps, main coolant line, surge lines, pressurizer and main steam lines and all the supports from the components/pipes to the building. These difficult and tedious efforts provided valuable insights into the system behavior under stress. Seismic motions were applied to the basemat of the containment building FE model and the forces and moments were developed in the pipe system through the support to the large components and piping. In these efforts, it was found that when circumferential through-wall cracks were put in the highest stressed locations (i.e., pipe weld to vessel nozzles), the applied moment dropped for both normal operating and N+SSE loading as the crack length increased. In fact, the moment dropped faster than the increase in crack driving force arising from the increase in the length of the crack. With loading 3 times higher than SSE loads, the through-wall crack size for causing a double ended guillotine break (DEGB) was greater than 90-percent of the circumference.

Similar results for a petrochemical plant have also been found, but with additional exploration of what happens if different pipe supports are damaged or there are temperature excursions to give much higher thermal expansion stresses (Wilkowski et al. 2018, Uddin et al. 2019). The petrochemical plant material had an extremely low toughness due to hydrogen attack (much lower than the nuclear piping materials evaluated), but because of the moment decrease with increasing circumferential through-wallcrack length, the critical crack size was a circumferential through-wall crack greater than $80 \%$ of the circumference.

These results will be presented in this paper with detailed insights as to why the applied moment decreases with increase of through-wall circumferential crack size. The potentially bounding worst-case condition for a pipe system would be one with very high inertial loading (i.e., unsupported loop isolation values) along with a low material fracture resistance (CF8m with high sensitivity to thermal aging or carbon steel that is very sensitive to dynamic strain-aging). The implication of this work is that pragmatically a DEGB is not a critical concern for nuclear plant operation, and efforts would be better focused on the potential for a small-break loss-of-coolant accident (SB-LOCA).

\section{PAST LBB TEST ON NUCLEAR PIPE SYSTEM}

In the IPIRG program (Wilkowski et al. 1997) funded by NRC, a dynamic pipe system test (Test\# 1.3-7) was conducted on a 100 feet long pipe system at $550 \mathrm{~F}$ and 2,250 psi pressure under simulated seismic loading. The pipe OD was 16 inch with 1 inch thickness and the pipe material was partially aged low toughness cast austenitic stainless steel $(\mathrm{CF} 8 \mathrm{~m})$. The initial flaw was a circumferential surface crack with crack depth over thickness (a/t) of $53.3 \%$ and crack length over circumference $(\theta / \pi)$ of $49.6 \%$. As it was not possible to apply such a large rotation to cause a DEGB in the pipe system (with all constraint boundary conditions), the rotations were cyclically ratcheted up increasing acceleration from $0.1 \mathrm{~g}$ (design) to $9 \mathrm{~g}$, so there was significant cyclic tearing and crack growth during the test. As shown in Figure 1, the surface crack penetrated through the thickness and became a through-wall crack after a total of 11 cycles after which the through-wall crack grew for another 13 cycles when DEGB occurred and a piece of pipe flew out of the building after knocking down the roof. One of the take away messages of this test from the LBB perspective is that the DEGB did not occur until circumferential through-wall crack reached $95 \%$ of the circumference as evident in Figure 2(a). A similar result was also found in another IPIRG test (Test 1.3-2) as shown in Figure 2(a) where DEGB occurred when the ligament was reduced to $3.3 \%$ to $5.5 \%$ of the circumference. However, simple limit-load and J-estimation procedures calculate much shorter critical through-wall crack lengths ( $60 \%$ of circumference) for Test 1.3-7. The 
actual critical through-wall crack length (95\% of the circumference) for this test is even larger than from just pressure load consideration using typical limit-load or EPFM assumptions. The reason for this was that in a pipe system the ends of the pipe are not free to rotate, so that bending moments induced from the pressure/endcap loading are restrained. This was not understood until a full nuclear steam supply system (NSSS) was analyzed using robust finite element modeling as described below.

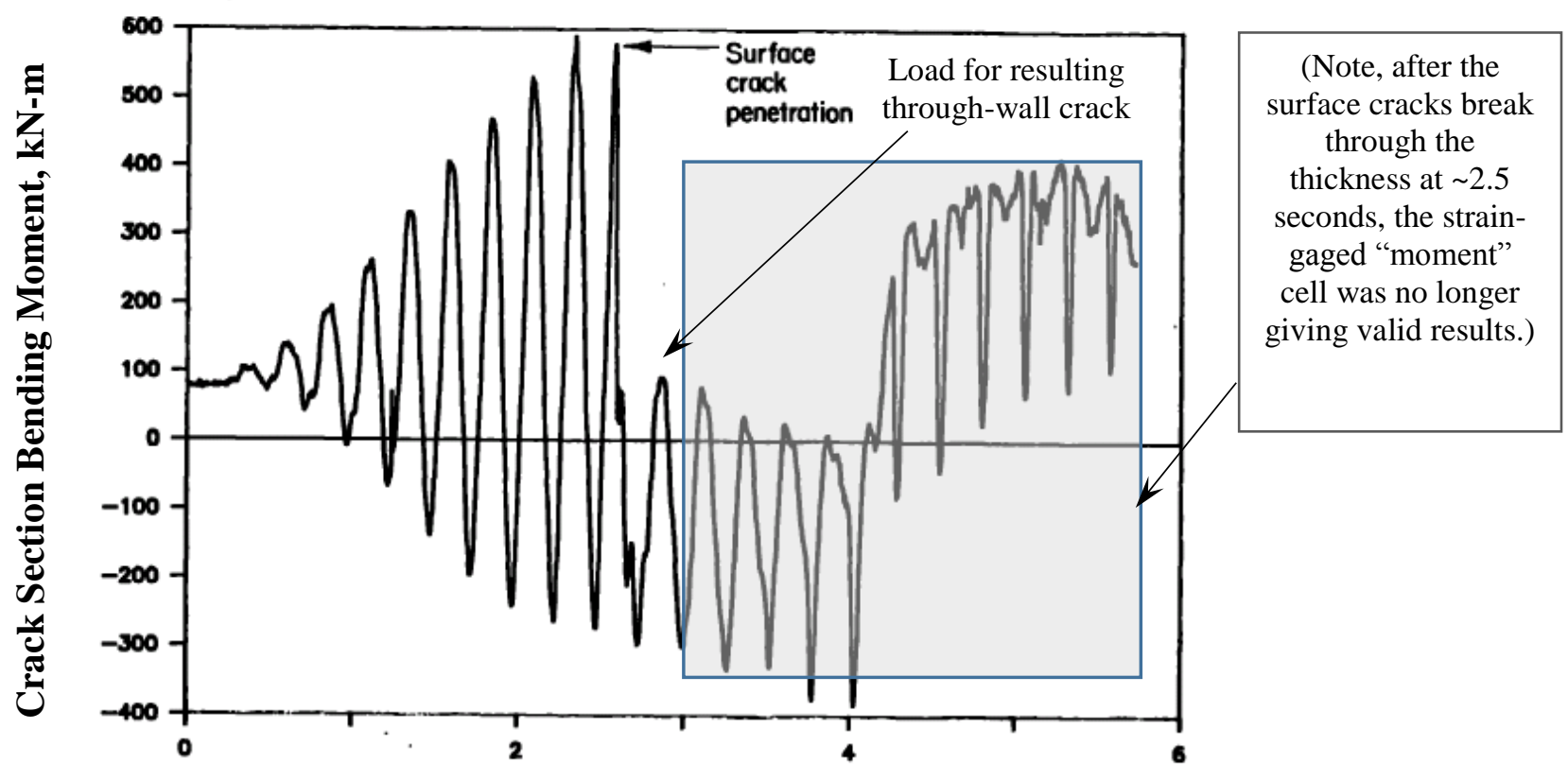

Time, seconds

Figure 1 Moment-time record from IPIRG-1 Experiment 1.3-7

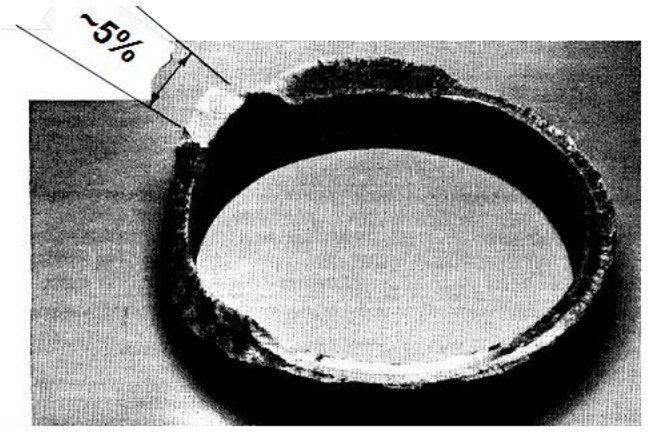

(a)

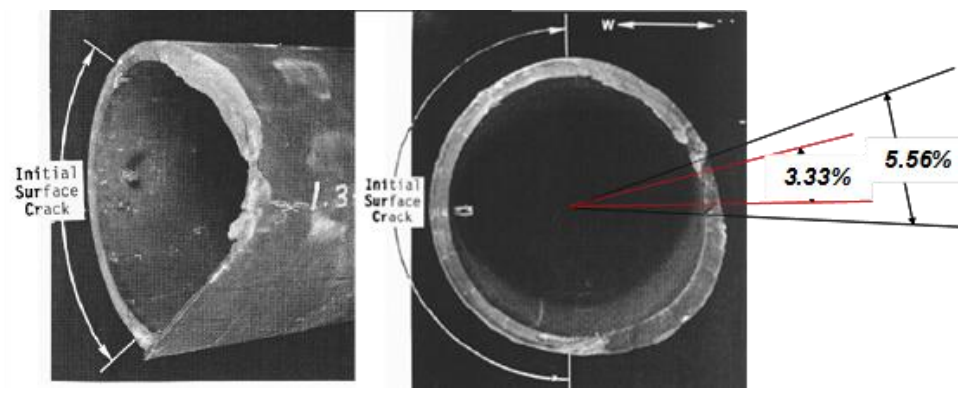

(b)

Figure 2 Fracture surface from IPIRG Experiments on 16-inch diameter pipe showing DEGB occurred when the ligament was reduced to (a) $\sim 5 \%$ of the circumference for Test $1.3-7$ (b) $3.3 \%$ to $5.5 \%$ of the circumference for Test $1.3-2$

\section{LBB USING FE MODELING OF PIPE SYSTEM}

As seen in these past experimental results, the critical through-wall crack length for DEGB was found to be much larger than those predicted by simple limit-load and J-estimation procedures. The reason for this mis-prediction was not understood until various finite element analyses (FEA) were conducted for entire piping systems for a nuclear power plant and a typical refinery piping system as described below. 


\section{FE Analysis of a Full Nuclear Steam Supply System (NSSS)}

A very large FE model was created for the entire NSSS of the Argentina Atucha II nuclear plant including the containment building, reactor pressure vessel, steam generator, pump, primary pipe loop, supports between the building and the components and piping ${ }^{1}$, see Figure 3. The details can be found in References [Wilkowski et al. 2011, Uddin et al. 2015, Uddin et al. 2014]. The loading was pressure, dead-weight, thermal expansion, and seismic excitation from the basemat of the containment building and then naturally transmitted though the supports to the components/piping. However, before starting to assess the LBB condition, one must ensure that a circumferential through-wall crack will develop from initial surface crack before it becomes a long surface crack, so that additional evaluations are not needed to determine if a long surface crack could develop into a rupture.

In doing so, an iterative FE analysis was conducted with the worst-case SCC crack growth rate observed in any nuclear plant (even though those materials were not used in the Argentina plant). The iterative FE approach crack shape modelling and some validations are described in detail in References [Shim et al. 2012 and Shim et al. 2010]. The high crack growth rate was used since the design was for 80 years of life. The weld residual stresses were determined using the welding procedures, including stress relieving for this ferritic weld case (most austenitic welds in nuclear plants are not stress relieved) and including clad thermal strain mismatch. Those stresses along with the normal operating stresses at various locations along the primary loop were used to calculate the crack shape as a function of time. Many validations of the weld residual stress modelling are included in various other references (Zhang et al. 2009, Smith et al. 2010). As seen in Figure 4, regardless of initial flaw shape, it always resulted in nearly-idealized circumferential through-wall-crack shape.

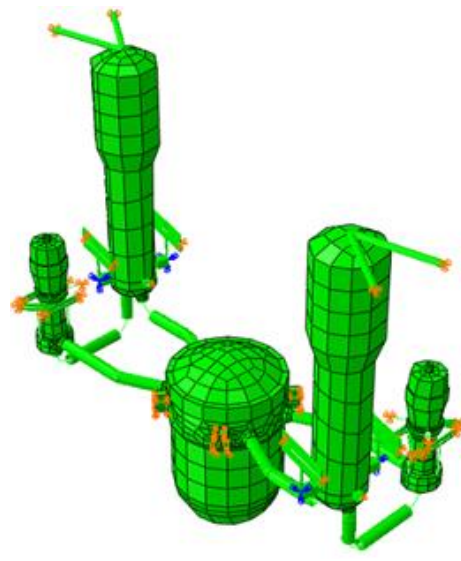

(a) NSSS system

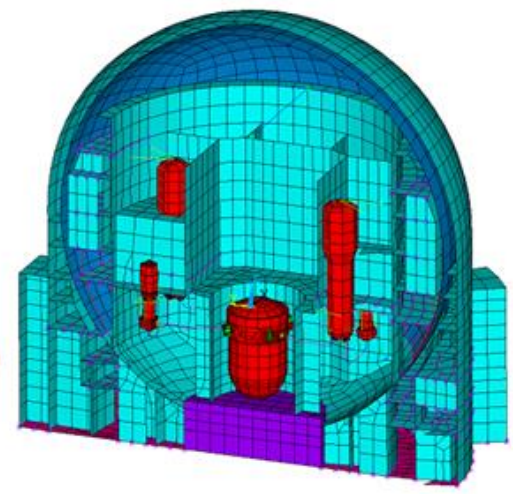

(b) With containment building

Figure 3 FE model of NSSS system and containment building of Atucha II nuclear plant, where cracks were inserted at critical locations by nozzles in the primary loop piping (Wilkowski et al. 2011)

The uncracked pipe peak stress was first used to determine a through-wall "critical" crack size. The crack was inserted in the FE model and centered on the high bending moment plane. After inserting the initial crack (based on it being "critical" using traditional LBB evaluation), it was found that the peak applied load was changed to a lower value than the uncracked pipe moment, see upper left graph in Figure 5. The circumferential through-wall crack was increased in length and in each step the load kept decreasing until the through-wall circumferential crack changed from the initial length of $15 \%$ of the circumference based on a typical LBB load-controlled analyses assumptions to being a circumferential

\footnotetext{
1 A further refinement to the Atucha nuclear system FE model included adding in the pressurizer vessel, surge line, main steam lines with supports and bellows connections to the containment building.
} 
length of $\sim 95 \%$ of the circumference when doing a fully pipe-system analysis with actual loading (see Figure 5 (a)).

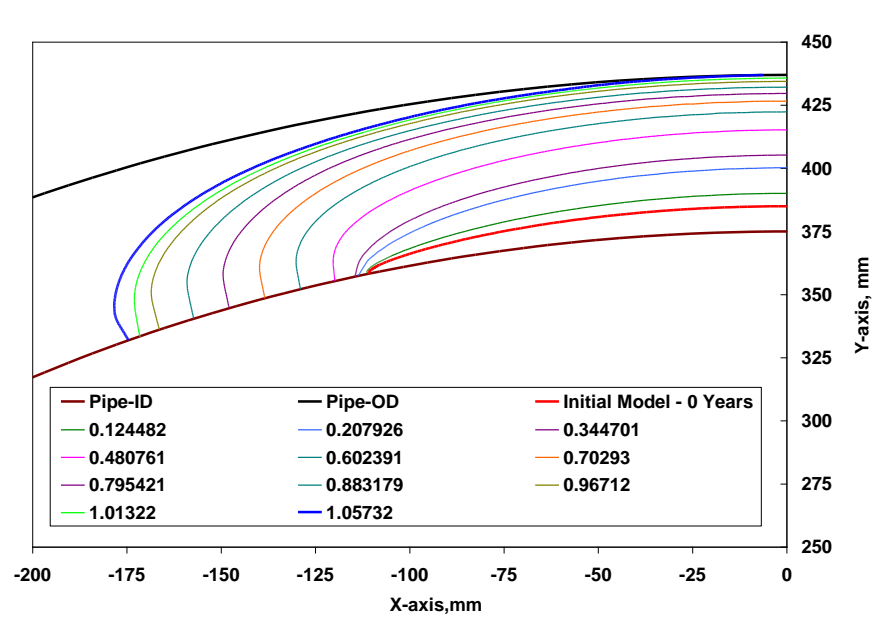

(a) Showing natural SCC flaw shapes up to incipient leakage from an initial flaw length of 5 times the maximum undetectable flaw length and maximum undetectable flaw depth

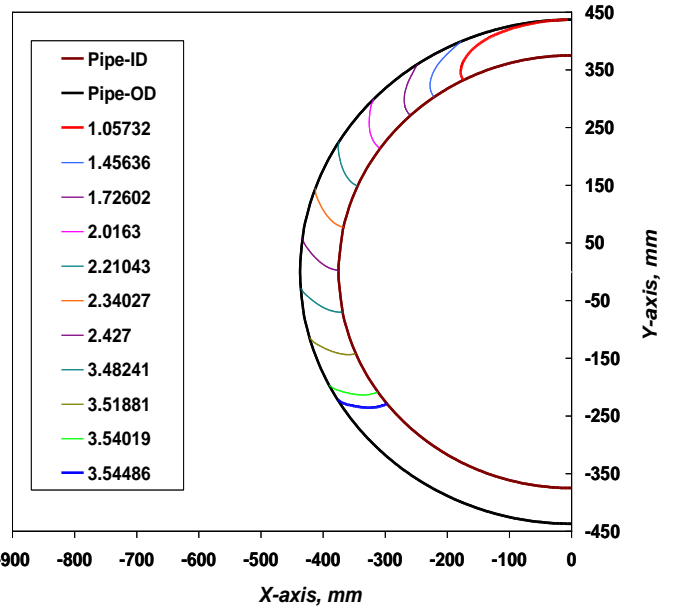

(b) Natural crack shape for large crack growth from the initial $5 *$ maximum undetectable length flaw i.e., initiation time for the starting SCC is not included)

Figure 4 Natural crack shape for large crack growth from surface crack to through-wall crack (Wilkowski et al. 2011), (legend is in years of crack growth)

The crack length was also much larger than from just pressure load consideration using typical limit-load or EPFM assumptions. The reason for this was that in a pipe system the ends of the pipe are not free to rotate, so that bending moments induced from the pressure/endcap loading are restrained. Illustrations of this effect are shown in Figure 2 where in pipe-system fracture experiments (Wilkowski et al. 1997) with internal pressure, thermal expansion and seismic loading the final DEGB did not occur until the crack lengths were about $95 \%$ of the circumference even though the traditional limit-load analysis calculated the critical through-wall-crack length to be $\sim 60 \%$ of the circumference. This crack size corresponded to the axial load from the pressure on the ligament that corresponds to an axial membrane stress equal to the material flow stress, which gives a revised limit-load criteria for pressure loads in a pipe system (Kalyanam et al. 2017).

In the nuclear industry the leakage of subcooled water is determined by a number of software codes, one of which is called SQUIRT (Paul et al. 1994, SQUIRT 2009). SQUIRT was developed for the US NRC, validated by many leak-rate tests, and was also used in the Atucha II evaluation in Reference [Wilkowski et al. 2011]. The crack was inserted in the FE model of the whole pipe system to determine the crack-opening area under normal operating loads, so it accounted for any restraint of the induced bending from the pressure loads. With the axial membrane loads not having the induced bending in a pipe system, the opening area is smaller than a typical calculation. The Atucha II plant had very good leakage detection capability (because of tritium in the water) which can easily detect leak rates much earlier than reaching the critical crack size for causing DEGB (see Figure 6(b)) and hence, LBB is satisfied with much larger margin. 

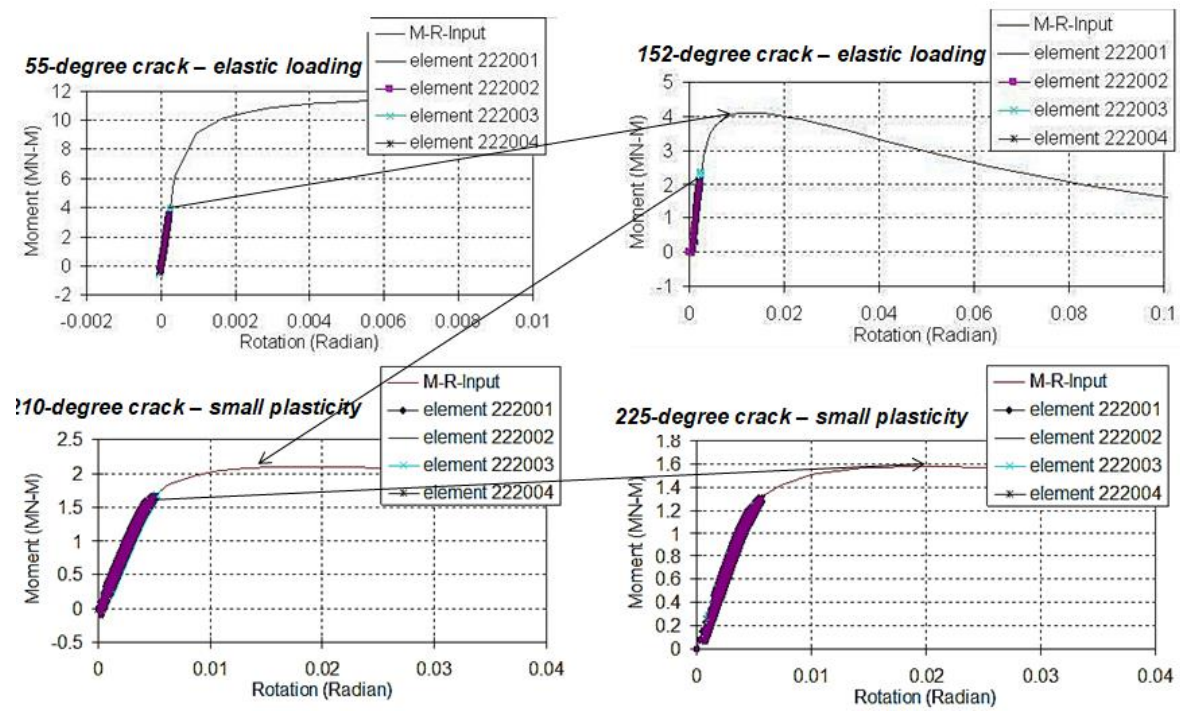

Figure 5 Illustration of how applied moments decreased with increasing circumferential through-wall crack length for same seismic load when modeling the cracked pipe in a complete pipe system for the Atucha II primary pipe loop (Wilkowski et al. 2011)

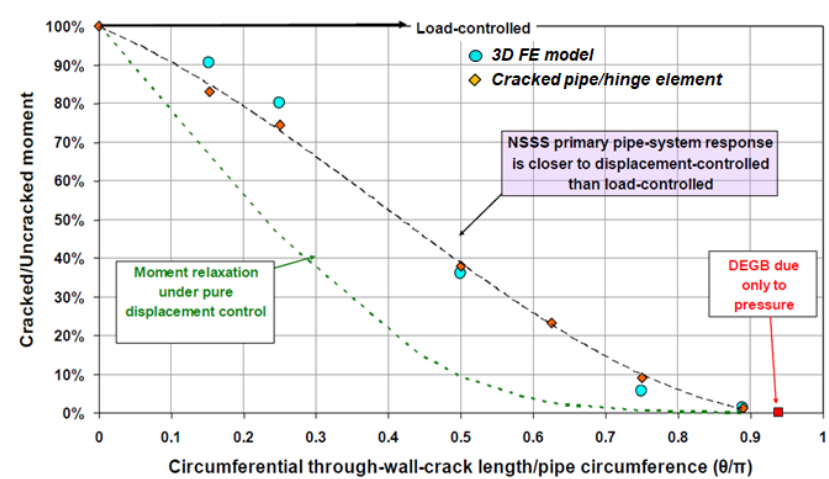

(a) Change in applied moments in pipe system with circumferential crack length in Atucha II primary pipe loop (Wilkowski et al. 2011, Uddin et al. 2014)

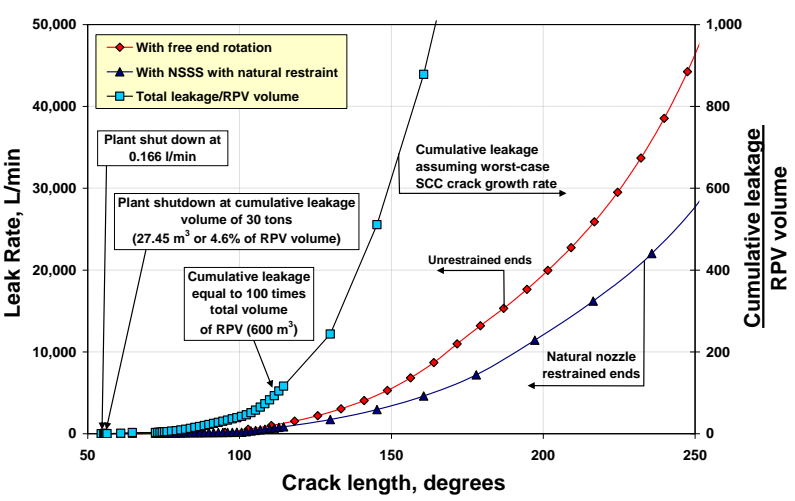

(b) Leak rates and total volume of water leaked for Atucha II plant in Reference [Wilkowski et al. 2011] Error! Bookmark not defined.

Figure 6 Change in applied moments and leak rates with circumferential crack size in Atucha II plant

\section{FE Analysis of a Typical Refinery Piping System}

Recently FE analysis of a typical (non-stress relieved) piping system sensitive to high temperature hydrogen attack (HTHA) cracking as shown in Error! Reference source not found. Figure 7 was conducted to explore conditions in which LBB can be applied, i.e. determine the critical flaw size and leakage analyses with its design boundary conditions under operating loadings, i.e., gravity, pressure (2.0 $\mathrm{MPa}$ ), thermal (316 C) and hanger loadings. Details can be found in References [Wilkowski et al. 2018, Uddin et al. 2019]. One side of the system contains a vessel. Typical boundary conditions for the piping system are shown in Figure 7Error! Reference source not found.(b) where all straight-pipe sections, elbows, and vessels are drawn in a wire diagram. The diameter and thickness of straight pipes and elbows 
are 18 inch $(457.2 \mathrm{~mm})$ and 0.5 inch $(12.7 \mathrm{~mm})$ respectively. For the sake of discussion, the piping system is labelled as Loop 1 and Loop 2. There are a total of twelve elbows in the piping system as well as flanges and valves whose masses are given in Figure 7Error! Reference source not found.(b). To offset the gravity loading two types of hanger supports are employed; constant-force hangers and variable-force hangers.

Similar to nuclear piping, FE analyses were also performed to study the development of throughwall cracks in refinery piping as they are typically much thinner than nuclear piping and the ferritic welds are made with much larger weld beads than nuclear plant piping. The residual stress analyses were conducted using a moving arc welding simulation so that there was a start and stop to each weld pass. Details can be found in Reference [Wilkowski et al. 2018]. Although realistically there are multiple stopstarts in making a Submerged Metal Arc Weld (SMAW) with varying time delays between a stop and start, we used only one stop-start per weld bead pass. Furthermore, as a sensitivity study for each weld bead layer, we staggered the stop-start positions of the weld, see Figure 8(a).

The weld simulation results were quite different than thick-shell or axisymmetric solutions for nuclear piping (both for as-welded conditions, i.e., no stress relieving). Some of the key differences were; (1) The as-welded transient start-stop stresses were controlled entirely with the start-stop position of the very last weld pass (315-degree position in Figure 8(a)), and (2) Additionally on the ID surface where HTHA would start, the as-welded stresses are tension on the thinner pipe side than the thicker fitting pipe side. Figure 8(b) shows the longitudinal as-welded residual stresses with the above observations. Hence from this analysis, a HTHA crack in non-stress relieved pipe is more likely to initiate and grow through the thickness at the stop region, continue to grow on one side of the weld, and have a region of no cracking near the start position of the weld where there are through-thickness compressive stresses.

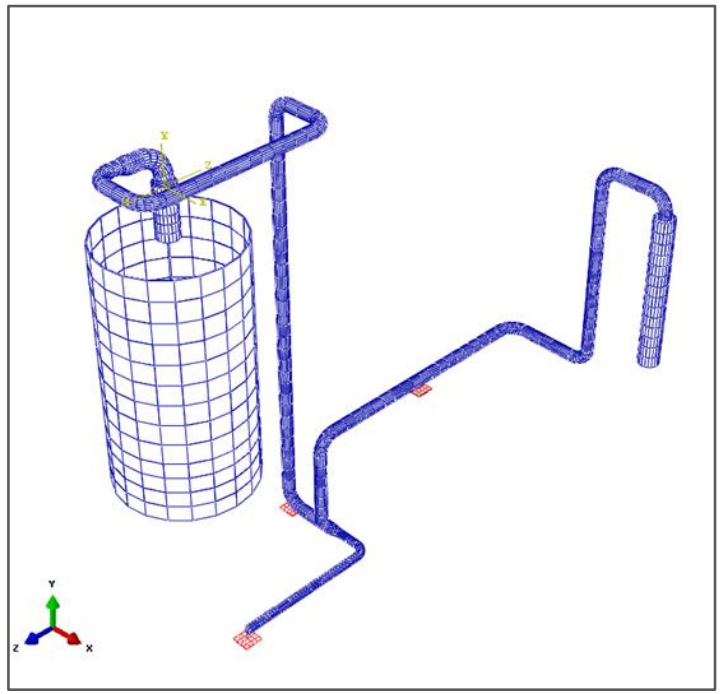

(a)

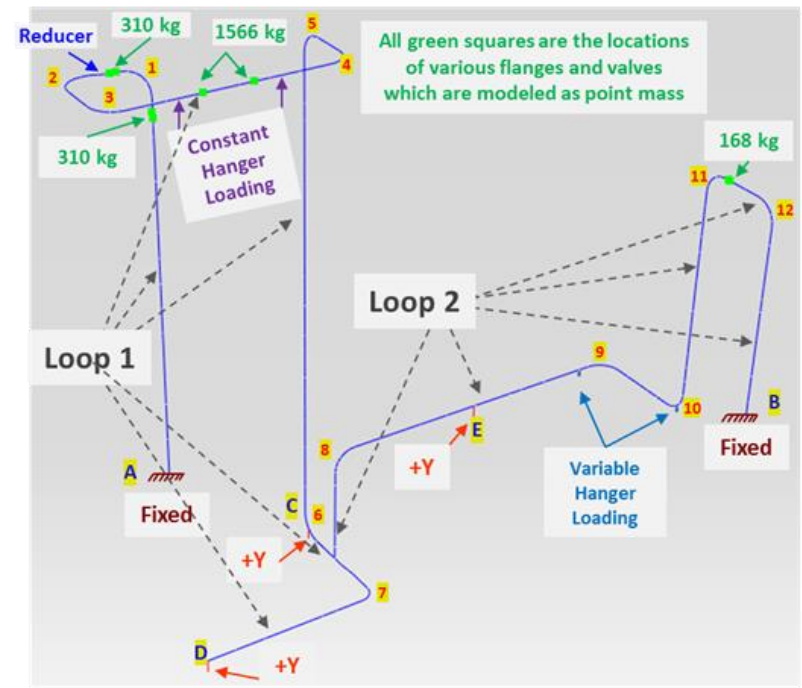

(b)

Figure 7 Typical refinery plant (non-stress relieved) piping system sensitive to HTHA cracking used in this study for critical flaw size and leakage analyses 


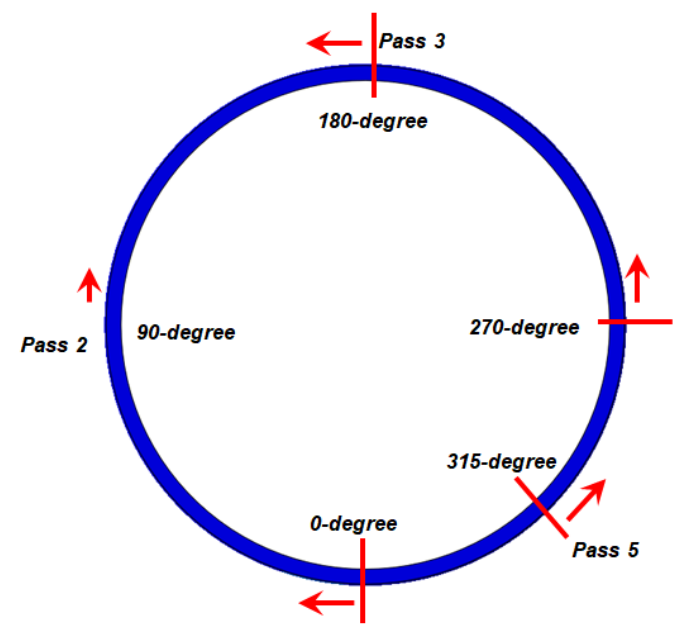

(a) Schematic of weld start-stop positions

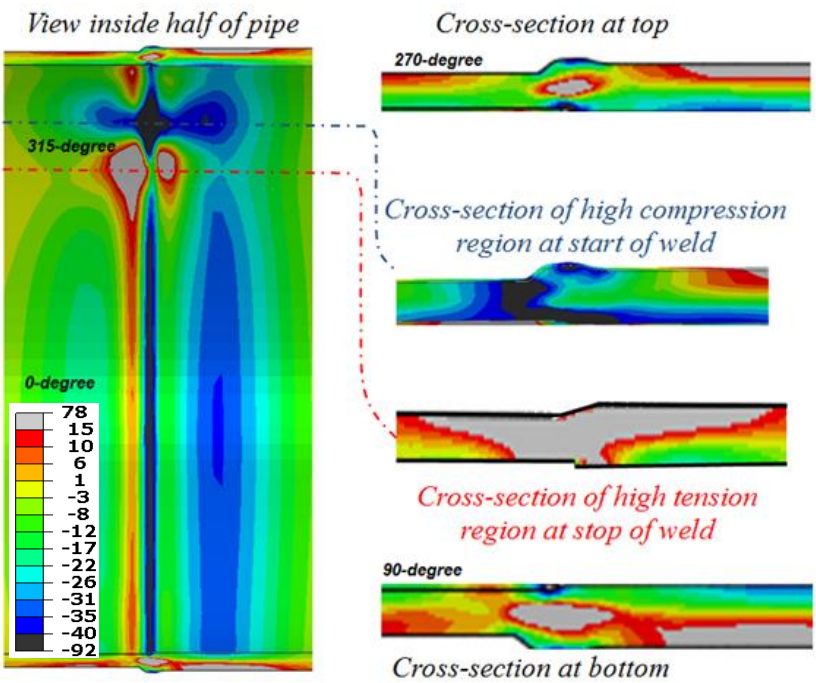

(b) Longitudinal stresses from as-welded residual stress FE analysis looking at ID of the pipe, and some cross sections $(k s i)$

Figure 8 Results of weld residual stress simulation (Wilkowski et al. 2018)

"Natural crack growth" simulations were then conducted with welds in the as-welded condition. An initial small surface crack was inserted in the highest as-welded transient residual stress region shown in Figure 8(b). A high HTHA crack growth rate based on very limited data from Reference [Shewmon et al. 1991] was used, see Figure 9. This growth rate is about 10 times larger than the fastest rate for the nuclear piping PWSCC degradation mechanism. The results of one time-step along the natural crack growth analysis showed the crack quickly became a through-wall crack which is reasonably close between the service crack.

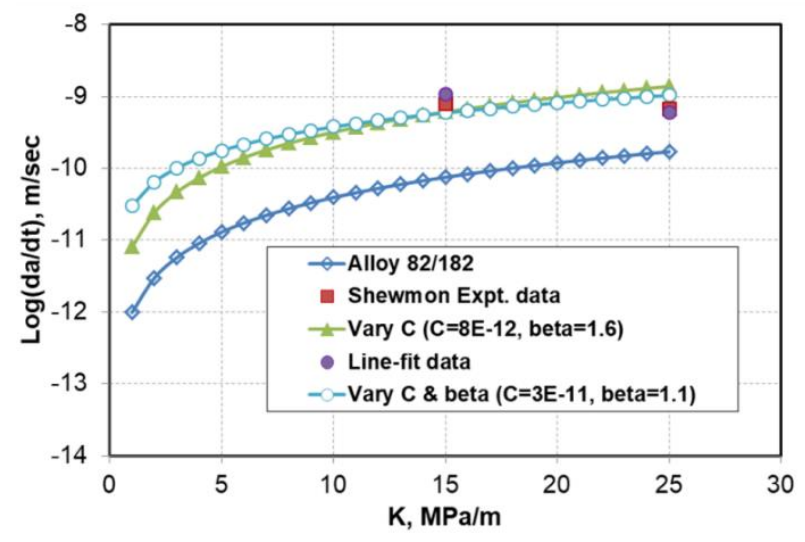

(a) HTHA crack growth rate used, from Reference [Shewmon et al. 1991] data

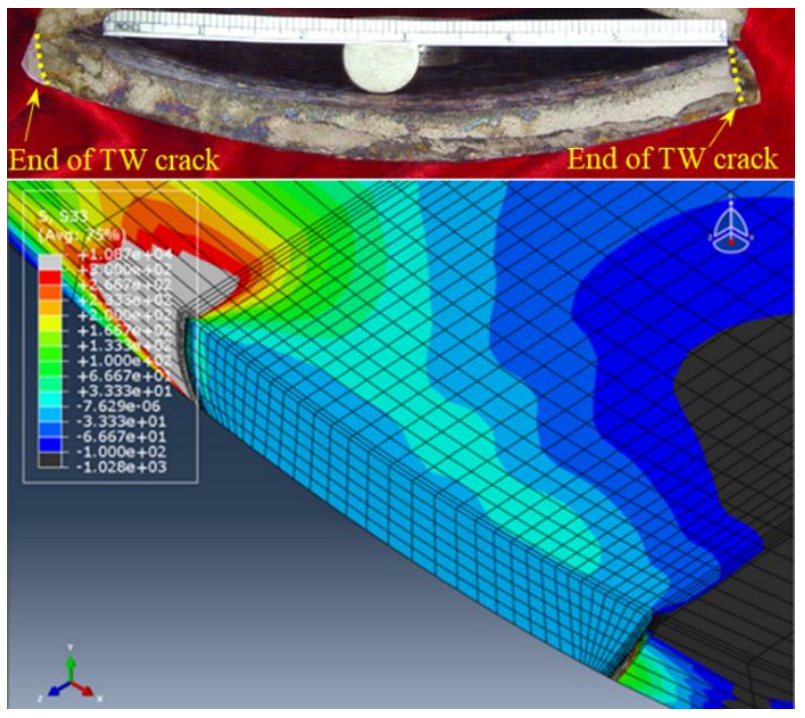

(a) Calculated natural crack growth shape at time step of 9.2 years from initial small surface flaw insertion

Figure 9 Results of natural crack growth simulation (Wilkowski et al. 2011) 
Circumferential through-wall cracks of various sizes were put in critical crack locations to determine the critical crack size using cracked-pipe system analyses. Note that critical crack locations of the pipe system were determined by running various stress analyses on the uncracked pipe system with various boundary conditions where the critical locations correspond to maximum effective moment locations of the pipe system. Four cases of cracked-pipe system were analyzed based on critical crack locations where cracks were found in service as well as the variation of loading conditions, i.e. combination of primary stresses (gravity, pressure) and secondary stresses (thermal). In order to include the effect of HTHA in the FE analyses, the lower bound A106B J-R curve (material toughness) at $288 \mathrm{C}$ was reduced by a factor of 0.25. Later, from single-edge-notched tension (SENT) tests of HTHA degraded A106B materials, it was found that the reduced lower-bound J-R curve was reasonably close to HTHA degraded A106B J-R curve.

For each crack size and crack location, the applied moment-rotation output from the pipe system analysis was extracted and compared with the moment capacity for the corresponding crack sizes. Some representative moment-rotation inputs and outputs are shown in Figure 10 and Figure 11. As seen in Figure 10 for Case 1 where the applied loading is mostly displacement-controlled, the applied moment in the pipe system is in the elastic range for all crack sizes indicating that the cracks at this location under Case 1 will not initiate even for a crack size of $80 \%$ of the circumference. On the other hand, the applied moment for Case 2 in the pipe system (see Figure 11) exceeds the elastic range and is beyond the maximum moment capacity of the crack for crack sizes greater than $71 \%$ of the circumference, although the crack became stable with significant crack growth. This indicates that the crack may start to have ductile tearing for crack size of about $53 \%$ of the circumference and the crack will grow in a ductile manner until it has a much longer length and very large crack opening for leakage.

The results of all four cases with five different crack sizes are summarized in Figure 12(a) where Case 1 and Case 5 correspond to primarily displacement-controlled (mostly thermal loading) and Case 2 and Case 4 correspond to primarily load-controlled (mostly gravity, pressure and hanger loading). It is pertinent to note that only Case 1 (displacement-controlled behavior) corresponds to actual design boundary condition whereas the other three cases were artificially simulated to capture the pipe system behavior in case of a support failure and/or hanger failure. As seen in Figure 12(a), two displacementcontrolled loading cases showed a significant drop in applied moment for smaller crack sizes relative to the uncracked pipe moment and then the moment drops gradually as the crack size increases, crack initiation and ductile crack growth would not occur until it reaches a crack size $(>80 \%$ of the circumference) when DEGB occurs due to internal pressure only - very similar to what was shown for Atucha II nuclear plant piping system. On the other hand, two load-controlled loading cases where primary stresses (gravity, pressure) are higher due to support/hanger failure showed somewhat different behavior where the applied moment does not drop much for smaller crack sizes and then the moment drops sharply after a certain crack sizes. Crack initiation and ductile crack growth may occur at a particular crack size before it reaches DEGB condition. Additional crack growth calculations would be necessary for those cases to evaluate the pipe system stability.

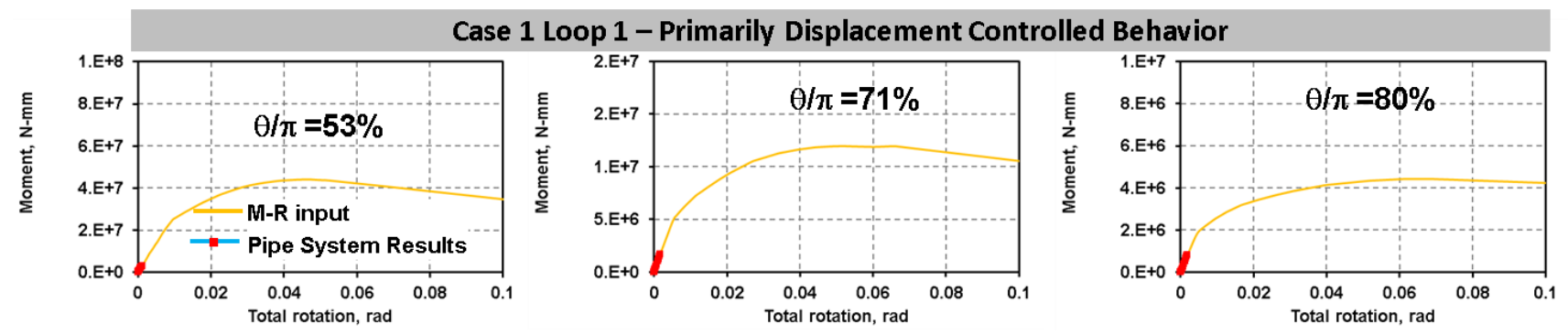

Figure 10 Illustration of how applied moments decreased with increasing circumferential through-wall crack length for mostly displacement-controlled loading 

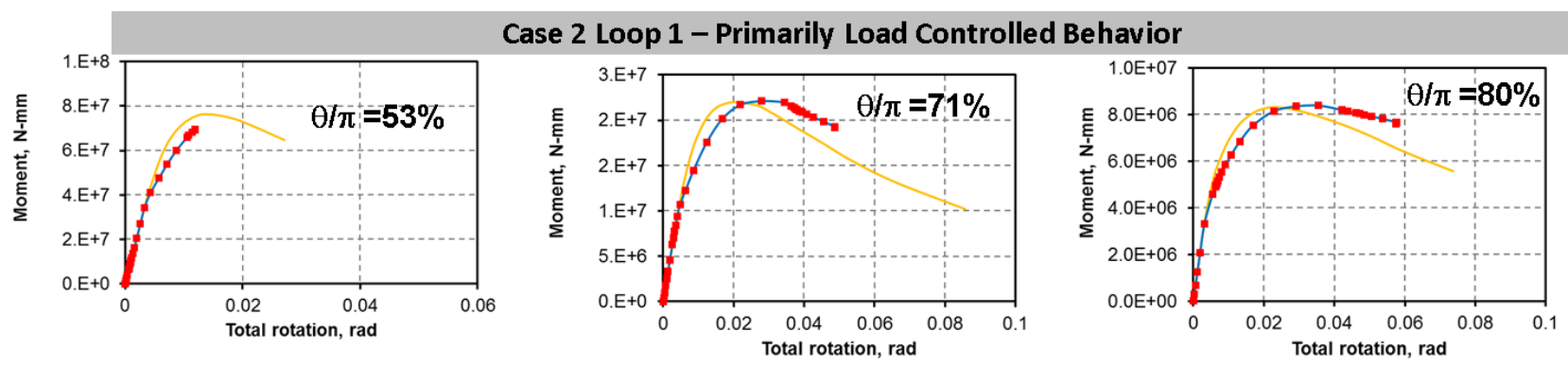

Figure 11 Illustration of how applied moments go beyond the maximum moment capacity with increasing circumferential through-wall crack length for mostly load-controlled loading

Finally, the moment capacities of the various circumferential crack lengths were calculated by the most accurate of the J-estimation procedure (LBB.ENG2) from the nuclear piping development and fullscale validation efforts (Wilkowski et al. 1998). The results are shown in Figure 12(b) which shows the tremendously large critical circumferential through-wall-flaw length $(>80 \%$ of the circumference) that can be tolerated in the pipe system for displacement-controlled behavior (Case 1 and Case 5) even with the lower-bound HTHA toughness and a safety factor of 3 on the applied thermal moments. However, the critical crack sizes for load-controlled cases (Case 2 and Case 4) due to support/hanger failure are much shorter (about $30 \%-58 \%$ of the circumference).

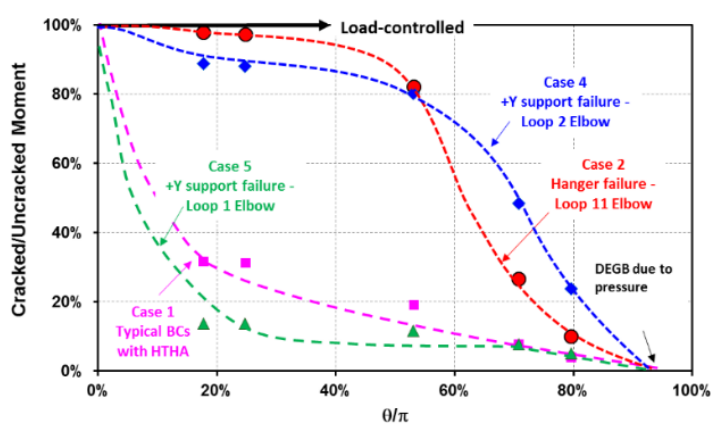

(a) Change of applied moments with various crack sizes under various boundary conditions

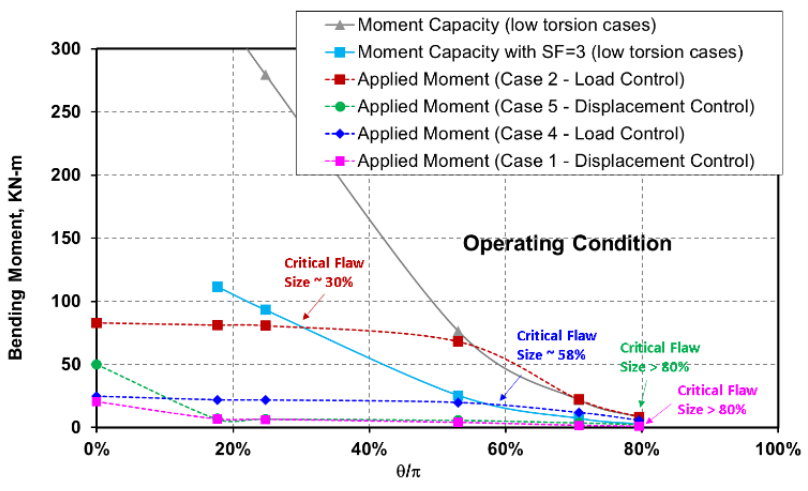

(b) Comparison of applied moments (from Figure 10) to critical flaw size with HTHA toughness reductions and safety factor of 3 on the maximum

Figure 12 Cracked-pipe system analyses of a typical refinery plant

Leak rates have been calculated for all five crack sizes for all four cases using the software code SQUIRT (Paul et al. 1994, SQUIRT 2009) mentioned in the previous section. The leakage rate is calculated using the crack length, COD, pipe size, and operating pressure and temperature as input. In all calculations the single-phase steam option was chosen since it corresponds more closely to the product in this pipe system. The crack morphology parameters of roughness, number of turns, and path deviation can impact the leak rate significantly. The thermal fatigue morphology most closely resembles the intergranular stress corrosion cracking (IGSCC) crack morphology and the default IGSCC crack morphology parameters were used for these calculations which appeared to be conservative compared to HTHA cracks. The leak detection capability of the current pipe system is less than 0.2 liter per minute (lpm) which corresponds to a leakage crack size of $25 \%$ of the circumference. As the critical crack lengths for all cases are greater than $25 \%$ of the circumference, LBB is satisfied for all cases. However, the margin for displacement-controlled cases is much higher than that for load-controlled cases. 


\section{CONCLUSION}

Detailed FE analysis of full nuclear steam supply system (NSSS) within a containment building with all of its components under normal operating and N+SSE conditions showed a large margin on LBB due to the fact that the pipe ends (of the system) are not free to rotate and hence the induced bending is restrained. The critical crack size for causing DEGB was greater than $90 \%$ of the circumference. A similar FE analysis was also conducted for a typical refinery piping system under operating loading conditions with a higher ratio of secondary (thermal) over primary (gravity, pressure) loading (design boundary condition). The analysis showed that the pipe system with design boundary conditions behaves similarly to the NSSS above - a displacement-controlled behavior where the induced bending is restrained. The final results showed a large margin on LBB where the critical crack size for causing DEGB is greater than $80 \%$ of the circumference. However, when a support and/or hanger failure were simulated for the refinery piping system, the system showed a load-controlled behavior and the margin on LBB was lower than that for displacement-controlled behavior.

Form the above analyses, it seems that there is a large margin in LBB in the pipe system when compared to performing LBB evaluation for a straight pipe section using limit-load and J-estimation scheme. The implication is that pragmatically a DEGB is not a critical concern for nuclear plant operation, and efforts would be better focused on the potential for a small-break loss-of-coolant accident (SB-LOCA).

\section{REFERENCES}

Kalyanam, S., Wilkowski, G., Pothana, S., Hioe, Y., Sallaberry, C. and Martin, J. (2017). “Apparent NetSection-Collapse Methodology for Circumferential Surface Flaws in Piping," Proceedings of the ASME 2017 Pressure Vessels \& Piping Conference, PVP2017-65438.

Paul, D. D., Ahmad, J., Scott, P. M., Flanigan, L., and Wilkowski, G. M., (1994). "Evaluation and Refinement of Leak-Rate Estimation Models," NUREG/CR-5128 Rev. 1.

Shewmon, P., and Xue, Y-H. (1991). "Effect of High-Pressure Hydrogen on Crack Growth in Carbon Steel," Metallurgical Transactions, Vol. 22A, 2703-2707.

Shim, D-J, Brust, F., Wilkowski, G. (2012). “Accounting for Natural Crack Growth Shapes during Environmental Cracking," paper \# IPC2012-90570, Proceedings of the 9th International Pipeline Conference - IPC2012.

Shim, D-J., Kalyanam, S., Punch, E., Zhang, T., Brust, F., Wilkowski, G., Goodfellow, A., Smith, M. (2010). "Advance Finite Element Analysis (AFEA) Evaluation for Circumferential and Axial PWSCC Defect," PVP2010-25162, ASME Pressure Vessel and Piping Conference.

Smith, M., Muransky, O., Goodfellow, A., Kingston, E., Freyer, P., Marlette, S., Wilkowski, G., Brust, F., Shim, D-J. (2010). "The Impact of Key Simulation Variables on Predicted Residual Stresses in Pressuriser Nozzle Dissimilar Metal Weld Mock-Ups," ASME Pressure Vessel and Piping Conference.

SQUIRT (Seepage Quantification of Upsets In Reactor Tubes), Version 2.1.3, Battelle Memorial Institute, Revision Date October 27, 2009.

Uddin, M., Wilkowski, G., Kurth, E., Hill, L., Bagnoli, K. (2019) "Modeling of Cracked Pipe System Effect of Boundary Conditions on Displacement-Controlled and Load-Controlled Leak-BeforeBreak", paper PVP2019-93927, Proceeding of the ASME 2019 Pressure Vessel and Piping Conference.

Uddin, M., Tombstone, E., Brust, F., Wilkowski, G. (2015). "Prediction of Dynamic Break-Opening Area Under Beyond Design Basis Seismic Loading”, PVP2015-45790, Proc. of ASME Pressure Vessels and Piping Conference, July 19-23,Boston, Massachusetts, USA. 
Uddin, M., Brust, F., Wilkowski, G., Zhang, T., Betervide, A. A., Mazzantini, O. , Fernandez, R. A. (2014). "Prediction of Margins in the TBS Seismic Considerations Analysis for Circumferential Surface-Cracked Piping under Beyond Design Basis Seismic Loading," paper \# PVP2014-28819, Proceedings of the ASME 2014 Pressure Vessels \& Piping Division Conference - PVP2014, July 20-24.

Wilkowski, G., Hioe, Y., Kurth, E., Punch, E., Uddin, M., Brust, F., Bagnoli, K., Pioszak, G. (2018). "Initial Developments for LBB Application to HTHA Sensitive Non-Stress Relieved Carbon Steel Girth Welds in Refinery Plants", paper PVP2018-84669, Proceeding of the ASME 2018 Pressure Vessel and Piping Conference.

Wilkowski, G. M., Brust, F. W., Zhang, T., Hattery, G., Kalyanam, S., Shim, D-J, Kurth, K, Hioe, Y., Uddin, M., Johnson, J. J., Asfura, A. P., Betervide, A. A., Mazzantini, O. (2011). "Robust LBB Analyses for Atucha II Nuclear Plant," paper \# PVP2011-57939, Proceeding of the ASME 2011 Pressure Vessel and Piping Conference.

Wilkowski, G. M., Olson, R. J., and Scott, P. M. (1998). "State-of-the-Art Report on Piping Fracture Mechanics,” U.S. Nuclear Regulatory Commission report NUREG/CR-6540, BMI-2196.

Wilkowski, G., Schmidt, R., Scott, P., Olson, R., Marschall, C., Kramer, G., Paul, D. (1997). "International Piping Integrity Research Group (IPIRG) Program," NUREG/CR-6233 Vol. 4.

Zhang, T., Brust, F., Wilkowski, G., Rudland, D., Csontos, A. (2009). "Welding Residual Stress and Multiple Flaw Evaluation for Reactor Pressure Vessel Head Replacement Welds with Alloy 52," 2009 ASME Pressure Vessels and Piping Division Conference, July 26-30, Prague, Czech Republic. 